ADRIAN PRAETZELLIS

MARY PRAETZELLIS

\section{A Connecticut Merchant in Chinadom: A Play in One Act}

\author{
ABSTRACT
}

By 1855 four of the five Chinese District Associations in California had offices and boardinghouses in Sacramento on I Street between Fifth and Sixth. Agents of these Chinese Associations nurtured important reciprocal relationships with Sacramento businessmen, including Josiah Gallup, a merchant from Connecticut. Gallup discovered his niche as a translator and middleman for the Chinese merchants of San Francisco and Sacramento. He helped them purchase real estate and supplies, transport miners and prostitutes to the gold fields, and negotiate with City officials. This is the story of Joshua Gallup and how he helped the Chinese get started in Sacramento.

\section{Act 1}

Dramatis Personae:

THE ARCHAEOLOGIST, an earnest, late 20th-century social scientist.

JOSIAH GALLUP, a Gold Rush-era merchant and lawyer (Figure 1).

\section{The Scene:}

A meeting room at The Society for Historical Archaeology Conference on Historical and Underwater Archaeology, Corpus Christi, Texas (1997). A young woman stands at the podium. She fiddles with her papers, coughs, and scans the audience in an appeal for quiet.

\section{The Dialogue:}

ARCHAEOLOGIST (stiffly and in a monotone): In December 1995, personnel from the Anthropological Studies Center at Sonoma State University undertook archaeological data recovery of a portion of Sacramento's historic Chinese District. This work was performed at the request

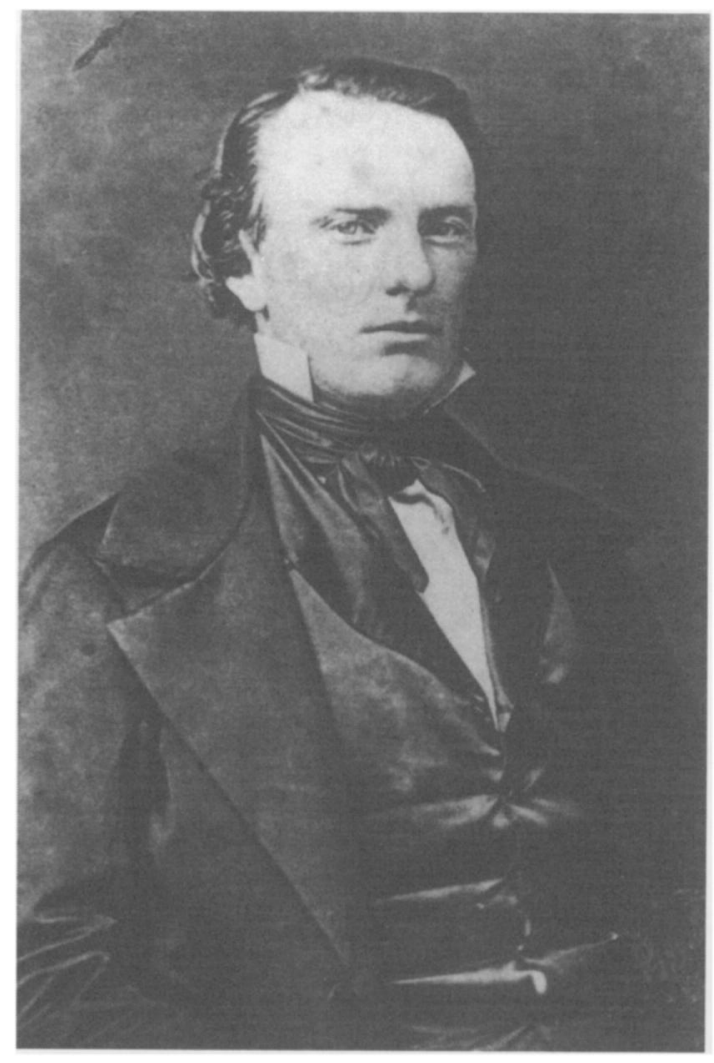

FIGURE 1. Josiah Gallup, 1826-1858. Connecticut-born, Gallup moved to Sacramento in 1849 where he acted as commission agent, translator, legal representative, and labor broker for several Chinese District Associations and companies in their dealings with local businesses and authorities. In letters to his fiancée, Gallup wrote of transporting Chinese immigrants from San Francisco to Sacramento where they would stay in boardinghouses until work was found for them in the goldfields. "About 300 Chinamen came up last night [and] the old dump is full . . ." (Gallup, 30 June 1854). Nearly 150 years later, archaeologists excavated the remains of "the old dump" and revealed a mixture of Chinese, American, and European artifacts that reflect both the milieu of the Gold Rush and Gallup's efforts as purchasing agent. (Courtesy of the California History Room, California State Library, Sacramento, CA.)

of the U.S. General Services Administration in accordance with the mandates of Section 106 of the National Historic Preservation Act. Implementing a research design based on 
postprocessual concepts, important data were recovered from the site that address issues of cultural innovation among the Overseas Chinese.

(From the rear of the room JOSIAH GALLUP, dressed in mid-19th-century costume, strides vigorously to front of the room, speaking to the audience as he walks.)

GALLUP: My God this is boring! And in life I was a lawyer .... and a City Alderman too. So let me assure you, I know the meaning of the word "dull." What is this young person talking about? I've always thought archaeologists went off studying Egyptian pyramids or some such, mummies and that sort of thing. Can't imagine why they'd want to poke around in Sacramento. Not enough real archaeology for 'em to do, I suppose.

(Evidently, the ARCHAEOLOGIST cannot hear this outburst, since she has not looked up from her text. She continues as before as GALLUP takes his place at the other podium. He eyes her skeptically.)

ARCHAEOLOGIST: During the early 1850s, the site was occupied by several Chinese District Associations, that built a series of boardinghouses for Chinese immigrants. Among these were the Yeung-wo, Ning Yeong, Sze Yap Company, and Sam Yap. These district associations arranged for the passage from China of thousands of workers, who would stay in the boardinghouses en route to the gold mining districts. In the racist climate of early California, the Chinese officials who ran their Associations' offices found it useful to employ agents in their dealings with the Americans. One of these agents was Josiah Gallup.

GALLUP (interrupting): That would be me. Born in Ledyard, Connecticut, 19th of November 1826 of an old merchant family, and a direct descendant of John Gallup, who landed on these shores in 1630. As a young man, I learned sufficient Chinese - of the Canton variety - to act as interpreter of that particular dialect of the Flowery Kingdom. In 1849 I went to California with the same two goals as almost every other man of my acquaintance: to make my pile and to go home. But we mortals are but servants to the
Divine Providence; and I should not have presumed to know His will. In the event, my life was taken by cholera in the summer of 1858 .

ARCHAEOLOGIST: Until his death at the age of 32 ...

GALLUP (interrupting): 31 . I was 31 -although I have unaccountably aged since then.

ARCHAEOLOGIST (continuing as if nothing had happened): . . . Gallup was the legal representative of several Chinese District Associations.

GALLUP: Legal representative. Now that sounds like I spent my days sitting at a desk with a pen behind my ear. It was nothing like that. But first, as a lawyer, I have to say that during the ' 50 s the Chinese had no legal standing in California. You see, on the assurances of experts in primitive culture and anatomy, the State Courts had classed the Chinese together with our own Indians, which made them ineligible to testify against a person of the White race. Bad for them, but good for me, since I took to acting as intermediary in the purchase of houses, land, or what you will. And also when there was any dealing with the Sheriff or City officials. Why, I even persuaded the mayor to let them have their New Year's parade with fireworks and such. Yes, and I'd buy supplies for them from American merchants some of whomshocking as it may seem-would actually raise their prices for Chinese and cheat 'em when they could.

ARCHAEOLOGIST: Gallup also owned teams of horses and wagons that he would use to bring the Chinese workers to Sacramento from the Chinese company boardinghouses in San Francisco . . .

GALLUP (interrupting): When they didn't come up the river by boat, that is. Two or three hundred at a time there might be. And oft times they'd stay for a few days in Sacramento, while I found them work in the gold mines. And we packed 'em into those boardinghouses, I can tell you. But on this topic, I will say a few words. Of late, there has been some uncharitable talk about these boardinghouses. So, if I may, I would translate for you the list of rules of the 
Yeung-wo house so you may decide for yourselves the moral character of these institutions. I begin: "In the company's house," it says, "there must be no concealment of stolen goods, no gunpowder or other combustible material, no gambling, no drunkenness, no cooking (except in the proper quarters), no burning of sacrificial papers, no accumulation of baggage, no filth, no bathing, no filching oil, no heaps of rags or trash, no wrangling or noise, no injury to company property, and no slops of victuals." And if that's not more rules than a temperance hotel, then I'm a Dutchman-which I'm not.

ARCHAEOLOGIST: The archaeological excavation was carried out using stratigraphic, open area methods. The deposits contained such a wealth of small artifacts and fish bone that the archaeologists bulk-bagged over six tons of the soil matrix for fine screening back at the lab.

GALLUP (incredulously): They collected what in bags?

ARCHAEOLOGIST (looks at GALLUP for the first and only time): Soil!

GALLUP (bewildered, to the audience): That's what I thought she said.

ARCHAEOLOGIST: These archaeological remains consisted of refuse-filled pits as well as layers of debris left by a fire that razed the block in 1855. The Sacramento Bee reported over $\$ 55,000$ in damages to a dozen Chinese businesses and their goods. The Bee also reported that Tong Achick, a leader of the Yeung-wo association, was caught stealing rice from an adjacent store under cover of the fire.

GALLUP (angrily thumps on the podium with his fist): Black slander! So this is your "history" is it? Nothing but gossip that has gained respectability by the passage of time-but as much of a lie now as it was in my day. Tong was a Christian gentleman. And a man with whom I did business for several years. He spoke English at least as well as any Texan and knew the ways of civilized society, both oriental and occidental. Why, in Hong Kong he served the British Consul General. I put no stock this nonsense about bags of rice-nor that other business with the prostitute. He was, after all, a Presbyterian. (Pensively) Yes, yes, yes, the fire of ' 55 . We believe that it started in one of the shops. Spread as fast as lightning. Burned the whole block down. Thousands of dollars lost. And would have been more, if some of the Chinese hadn't gotten their merchandise out into the street and saved it. It was a black day. But I had them bring all their goods over to my yard, and there it all sat until I found temporary quarters for them. Now to those who complain about the scandalous conditions in Chinatown that led to this awful conflagration, I would remind them that my clients' landlords included a judge, a city councilman, and other respected citizens, whom delicacy prevents me from naming.

ARCHAEOLOGIST (who still hasn't noticed GALLUP): Some historical archaeologists have claimed that the proportional relationship between Chinese and non-Chinese artifacts at an Overseas Chinese site will reflect the relative level of cultural change that the residents were subject to; a sort of material index of cultural change. Since Chinese-made artifacts dominate most early assemblages, it appears that this group vigorously maintained their traditional culture and largely ignored the non-Chinese world. However, this view is not supported by the data from this site. If one begins from the perspective of this socalled acculturation model, the ceramic data from the fire deposit are quite puzzling. Nearly 60 percent of the ceramic vessels from this context are English transfer prints or white earthenwares, while only 40 percent are Chinese. Other features on the site from the same period have similar contents, including transfer-printed vessels actually marked with a Chinese character denoting ownership. Do these lopsided figures indicate that the Chinese merchants and boardinghouse residents had taken on Victorian sensibilities? What do these artifacts mean? What are they telling us?

GALLUP (scoffing): Now, what nonsense is this? How may a plate be said to tell us anything? In all my travels I've never heard of communion between items of dinner ware and diners. 
Of discussions between bowls. Of heated debates between a tureen and a slop jar, perhaps. "Ah yes, the butter dish was most eloquent on the subject of the Irish Question, don't you think?" Now, my experience as one who was actually present at the time may better inform one of the speculations that have been presented by our scientist. First, the assertion that the denizens of the Chinese Quarter kept entirely to themselves, in their own little world. Balderdash! Of course, the lower classes of Chinese had little or nothing to do with any Americans, but the merchants and company agents like my friend Tong were as sophisticated as any men of my acquaintance. These were not fools. They knew that they needed influential friends to get by in California. There's even a word for it in Chinese: "guanxi." Let me explain. Guanxi is a network of family and business relationships tied together by bonds of trust, of obligation, and of reciprocity that in China are strong bonds indeed. In this way, a man's honor is linked to that of his family. The guanxi network of my friend Tong, for example, included his own immediate family, the many other merchants from his home of Hong Kong who were members of the Yeung-wo District Association, and people like me, who had their own friends and contacts in society. Every year the Chinese merchants would host a banquet for their American friends to reinforce their guanxi relationship and to show, perhaps, that Chinese are not so different from Americans in their belief in Christian virtues. Listen to this piece from that rag, the Sacramento Bee. I begin:

Last evening, on invitation, the writer was one of a dinner party, hosted by some of our leading Chinese merchants, and consisting of a county judge, a justice of the peace, a federal official, a physician, a West Pointer, a lawyer and ourself. On one wall hung a painting of a Chinese panther and the likenesses of 4 of the 8 Chinese Wandering Jews of the Celestial spheres. We had hoped for the pleasure of eating with chopsticks but none were observed. The table was set with cloth, knives, forks, plates, spoons, and napkins,

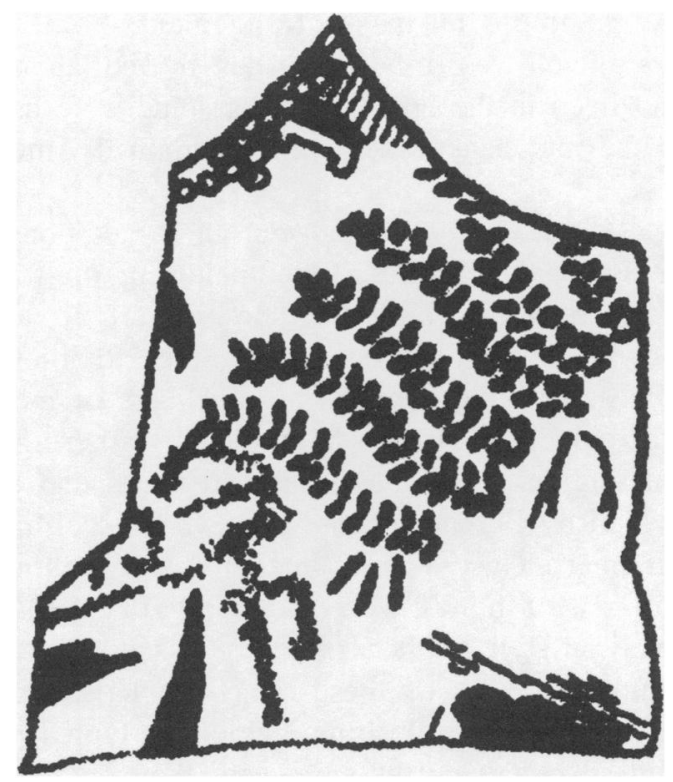

FIGURE 2. English "Willow" pattern plate fragment $(3.4 \mathrm{~cm}$ wide) with an incised Chinese character. Ownership marks such as this are not uncommon on ceramics from Overseas Chinese sites. However, finding one on a piece of Victorian chinoiserie makes us wonder how its owners obtained the plate and how they conceived of this and the other Staffordshire products in their household. With the discovery that agent Josiah Gallup purchased many of the mundane items for the household, this sherd came to be an icon of this study in historical archaeology. (Graphic by Maria Ribiero.)

and with celery in glasses and salt in cellars, very much like ordinary tables. Twenty-four courses were served, and every course had its own plate, spoon, etc. Although champagne was brought on several times, the brands were all different, and all first class (Sacramento Bee 12/ $7 / 1861)$.

Now what other nonsense was this person saying? Ah yes. That because the Chinese were using English pottery in the boardinghouse that they were somehow becoming like white Americans. Very pretty logic. Except that I was the man who bought the pottery, not them. When the house needed potatoes, I bought potatoes. When the house needed plates, I bought them plates. It 
was a simple business arrangement. Some of these items were used every day by the laborers who lived in the boardinghouse; some were used by the merchants when they entertained Americans.

ARCHAEOLOGIST (earnestly): In addition to the unusual ceramics, the butchering on food bone from this site does not adhere to any known ethnic Chinese pattern. Since traditional Chinese cooking employs small slivers of meat, one expects to find whole bones, rather than bones representing the steaks and roasts that are favored by Euroamericans. However, faunal analyst Sherri Gust reported that the overwhelming majority of bones were butchered in standard American style into steaks and roast-size portions. Strangely, many of these bones do have knife scores left by defleshing, which is typical of Chinese practice. But why were they obtaining meat cut American-style and then rebutchering it in the Chinese pattern? Is this evidence of a kind of cultural blending?

GALLUP: Here again, my friends, our scientist would do well to ask who was purchasing the meat. The answer: me-at least in part. Sometimes, you see, when the house was full, they would order whole carcasses. When there were few men, smaller pieces would suffice. Of course, I took my commission either way.

ARCHAEOLOGIST (puzzled): In conclusion, I have to admit that we have no convincing explanations for the unusual mixture of Asian and Euroamerican artifacts from this site. Contamination seems as unlikely as rapid cultural change .

GALLUP: And in conclusion, I do have some explanations. My Chinese clients were not becoming more like Americans just because they were using English plates and getting meat from American butchers. Just the reverse. Using these

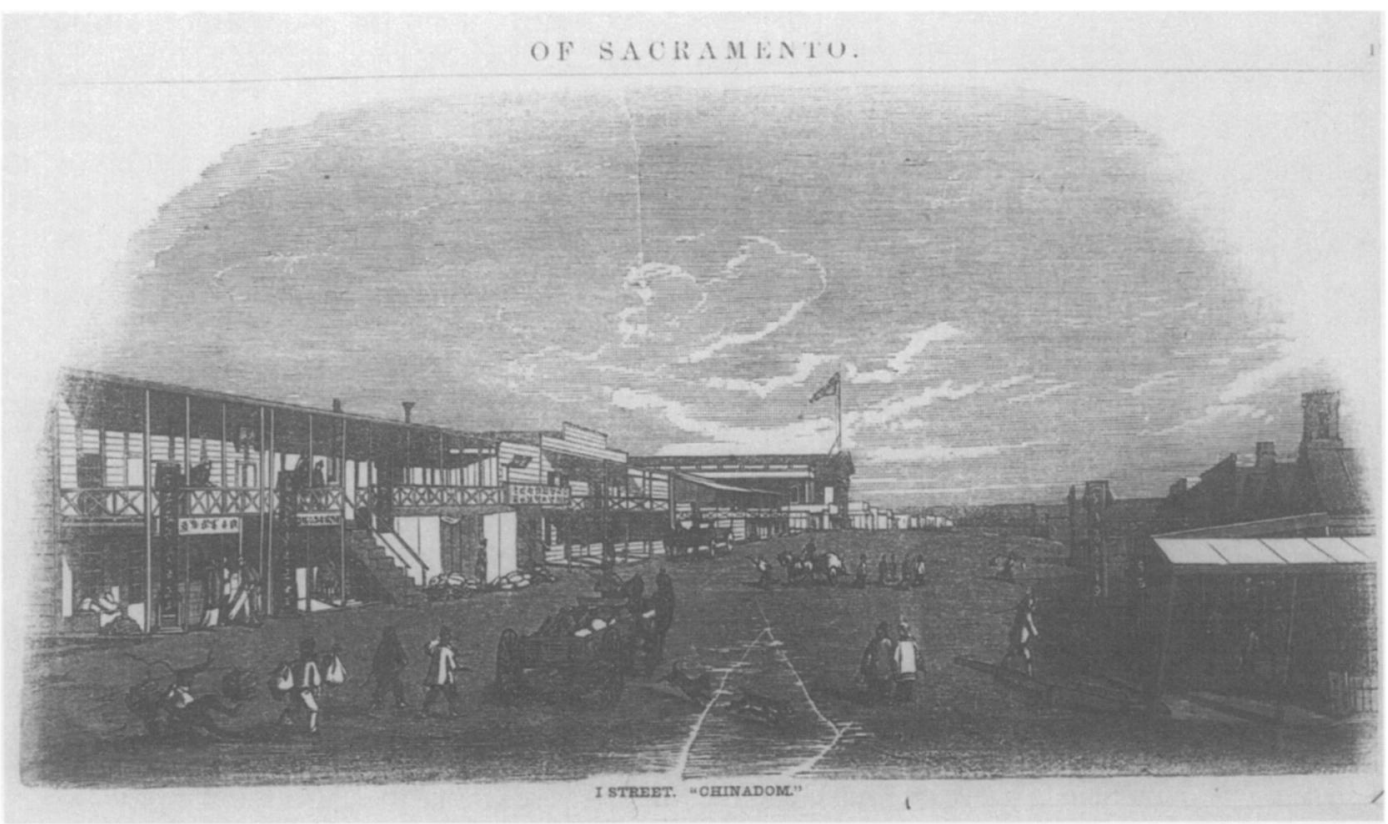

FIGURE 3. "I Street, Chinadom" looking east along I Street between 5th and 6th streets. The center of Sacramento's Chinese district, I Street was constructed on top of a 12-foot-high levee that sought to protect the low-lying city from floods that regularly inundated the downtown area. The businesses and boardinghouses on the left side of the street backed up onto fetid China Lake. These buildings were razed by fire in the summer of 1855 and the remains excavated by archaeologists in 1995. (Lithograph from Barber and Baker [1855]; courtesy of the California History Room, California State Library, Sacramento, CA.) 
TABLE 1

\section{CHINESE AND NON-CHINESE CERAMIC TABLE AND SERVING VESSELS FROM CHINESE ASSOCIATED CONTEXTS, HI56 BLOCK EXCAVATIONS, SACRAMENTO, CA}

Ceramic Type

Number/Minimum Number of Individuals

\begin{tabular}{lrrrrr} 
& Pit 979 & Layer 903 & Pit 16 & Pit 953 & Pit 702 \\
\hline Chinese & $10 / 3$ & $37 / 17$ & $40 / 8$ & $31 / 13$ & $59 / 15$ \\
Non-Chinese & $15 / 9$ & $91 / 24$ & $93 / 15$ & $17 / 10$ & $30 / 8$
\end{tabular}

Note. The contexts shown here date to the mid- and late 1850s. Layer 903 was the product of a fire that leveled the block in 1855; the remainder are from refuse-filled pits. Although the historic record is unequivocal in documenting that the area was occupied by Chinese businesses and boardinghouses at that time, the archaeological evidence shows that the residents used similar proportions of Chinese and, mostly, English ceramics.

items were matters of Chinese practicality and that traditional Chinese institution called guanxi. So if these blue Willow plates can be said to tell us anything, it is not that their owners were changing in habit and thought, but that they were adaptable and wise enough to use alien objects for very Chinese purposes (Table 1; Figure 2).

ARCHAEOLOGIST: And so, ladies and gentlemen, this concludes my presentation. I thank you very much for your attention.

GALLUP (bowing): And so do I.

(There is tumultuous applause from the audience. Flushed with success, both figures step down from the stage and go straight to the hotel bar where they are treated to several rounds of drinks by their admirers.)

\section{Bibliographic Essay}

A Connecticut Merchant in Chinadom explores relationships between the Chinese and non-Chinese populations of Gold Rush era California (Figure 3). Many of the principal players on this historic stage were Chinese merchants who, as a group, have traded and made their homes throughout Asia for centuries. Thus, it makes sense to begin by examining the culture of this group. The ethnographic context was provided by Omohundru's studies, Trading Patterns of Philippine Chinese (Omohundru 1978) and Chinese Merchant Families in Iloilo (Omohundru 1981), among other works, which focus on the ways in which Overseas Chinese communities are structured and how merchants have emerged as intermediaries or culture brokers between the Chinese and host populations. The system of relationships, known as guanxi, that ties Chinese business partners to each other and to non-Chinese facilitators, such as Josiah Gallup, is explored by Yang (1994) in her book Gifts, Favors, and Banquets. Lydon (1996) appears to be the first to have applied this concept to the interpretation of archaeological remains in Many Inventions, her study of Chinese merchants in Sydney, Australia.

The general historical context for the ethnic Chinese who flocked to California in the early $1850 \mathrm{~s}$ is provided by Barth's (1964) Bitter Strength which, although rather dated, still provides a good overview of the era and the role of the Chinese District Associations. Using evocative accounts from 19th-century newspapers, Heizer and Almquist's (1971) The Other Californians documents the discriminatory practices and attitudes that had a great influence on the way in which Chinese immigrants to California interacted with the wider community. Yet, lest anyone should think that Chinese leaders sat idly by while racist laws were passed, McClain's (1994) In Search of Equity shows that this group was both sophisticated and proactive in its efforts to make its voice heard in the councils of the powerful. 
The immediate historical context for the businesses and residences that were the subject of our archaeological project was constructed from a plethora of primary sources: newspaper accounts (e.g., Sacramento Bee 1857-1866; Sacramento Daily Democrat 1855-1862), official records, legal cases (e.g., Gallup vs. Young Wo 1856), personal correspondence, and city directories (Sacramento City Directory 1851-1912). These records allowed us to link people with places at specific times in the past, giving names and faces to the people whose artifacts we have discovered. The City of Sacramento's Books of Deeds (Sacramento Recorder's Office 1850-1860), Tax Assessment Rolls and Maps (Sacramento City and County 1851-1912), Water Tappers' Records (Sacramento City Tapper's Book 1854-1857), Business Licenses (Sacramento City Tax Collector's Business License Day Book 18631877), Probate (Gallup 1862), and other records are invaluable records of the city's early history. They are maintained by the Sacramento Archives and Museum Collection Center. The California History Room of the California State Library has a collection of letters, business papers, and photographs that relate to the life of Josiah Gallup (Gallup 1853-1854). These materials, which include letters from Gallup to his fiancée, Julia, gave us confidence in our assertions about the nature of the relationship between Gallup and his Chinese partners that we had deduced from ethnographic analogy. The life of Tong Achick, Gallup's equivalent as an intermediary in the Yeung-wo District Association, is documented by $\mathrm{Ng}$ (1995) and in The Oriental (1855), an English-language newspaper devoted to ChineseAmerican concerns.

The archaeological context for $A$ Connecticut Merchant in Chinadom derived from: records produced by the excavators of the HI56 block in Sacramento, stratigraphic analyses of specific features that created assemblages that we could confidently associate with particular social units at certain times in the past, and the analyses of artifact specialists. These records are on file at the Archaeological Collections Facility at Sonoma
State University. The technical report on the excavations, Historical Archaeology of an Overseas Chinese Community (Praetzellis and Praetzellis 1997), contains a detailed description of the site's structure and content.

\section{ACKNOWLEDGMENTS}

We would like to thank Anmarie Medin, a hard-working archaeologist at the Anthropological Studies Center, Sonoma State University, and Adrian's costar in the first performance of this work at the SHA meetings in Corpus Christi.

\section{REFERENCES}

Barber, Edmund L., ANd George BAKer

1855 Sacramento Illustrated. Barber and Baker, Sacramento, CA.

BARTH, GUNTHER

1964 Bitter Strength: A History of the Chinese in the United States, 1850-1870. Harvard University Press, Cambridge, MA.

Gallup, JosiaH

1853- Bio Info File. A collection of 50 letters, most dating to

1854 1853-1854. Box 202. California History Room, State Library, Sacramento.

1862 Probate File. Superior Court Case No. 475. On file, Sacramento Archives and Museum Collection Center, Sacramento, CA.

GALLUP, JOSIAH VS. THE YOUNG WO COMPANY

1856 Lawsuit in District Court, 6th Judicial District. Case No. 4747. On file, Sacramento Archives and Museum Collection Center, Sacramento, CA.

Heizer, Robert F., And Alan J. Almquist

1971 The Other Californians. University of California Press, Berkeley.

LYDON, JANE

1996 "Many Inventions": Historical Archaeology and the Chinese on the Rocks, Sydney, 1890-1930. Unpublished M.A. thesis, Department of History, Australian National University, Canberra, Australia.

McClain, Charles

1994 In Search of Equity. University of California Press, Berkeley.

NG, Frank (EDITOR)

1995 Tong K. Achick. In Asian American Encyclopedia, 
edited by Franklin Ng, pp. 1497-1499. Marshall Cavendish, North Bellmore, NY.

OMOHUNDRU, J. T.

1978 Trading Patterns of Philippine Chinese: Strategies of Sojourning Middlemen. In Economic Exchange and Social Interaction in Southeast Asia: Perspectives from Prehistory, History, and Ethnography, edited by K. Hunter. Michigan Papers on South and Southeast Asia 13:113-136. Ann Arbor.

1981 Chinese Merchant Families in Iloilo. Ohio University Press, Athens.

\section{ORIENTAL, THE}

1855 The Oriental or Tung-Ngai San Luk, edited by William Speer. Published weekly in English and Chinese. Whitton, Towne \& Co., San Francisco, CA. Microfilm on file, Bancroft Library, University of California, Berkeley.

Praetzellis, Mary, and Adrian Praetzellis

1997 Historical Archaeology of an Overseas Chinese Community in Sacramento, California, with contributions by Sherri Gust, Virginia Hellmann, Madeline Hirn, Sunshine Psota, Lester Ross, Peter Schulz, James West, and Jeannie Yang. Anthropological Studies Center, Sonoma State University, Rohnert Park, CA.

\section{SACRAMENTO BEE}

1857- Sacramento Bee. California History Room, State 1866 Library, Sacramento. Microfilm.

\section{SACRAMENTo City and CounTy}

1851- Tax Assessment Rolls and Maps. On file, Sacramento

1912 Archives and Museum Collection Center, Sacramento, CA.
SaCramento City Directory 1851-Sacramento City Directories. [Titles and publishers 1920 vary from year to year]. On file, California History Room, State Library, Sacramento.

\section{Sacramento City Tax Collector's Business License}

DAY BOOK

1863- Register. On file, Sacramento Archives and Museum 1877 Collection Center, Sacramento, CA.

SACRAMENTO DAILY DEMOCRATIC STATE JOURNAL 1855- Sacramento Daily Democratic State Journal.

1862 California History Room, State Library, Sacramento. Microfilm.

SACRAMENTo ReCorder's OfFice

1850 - Deeds. Sacramento Recorder's Office, Sacramento, 1860 CA.

\section{Sacramento City Secretary of Common Council's}

QUARTERLY LICENSE

1854- Register. On file, Sacramento Archives and Museum 1858 Collection Center, Sacramento, CA.

SaCramento City Tapper's Book 1854- Ledger. On file, Sacramento Archives and Museum 1857 Collection Center, Sacramento, CA.

YANG, MAYFAIR

1994 Gifts, Favors, and Banquets. Cornell University Press, Ithaca, NY.

\author{
Adrian Praetzellis \\ Mary Praetzellis \\ Department of ANThropology \\ Anthropological Studies CEnTER \\ Sonoma State University \\ ROHNERT PARK, CA 94928
}

